\title{
Article \\ Trends in Outpatient Prescribing Patterns for Ocular Topical Anti-Infectives in Six Major Areas of China, 2013-2019
}

\author{
Zhenwei $\mathrm{Yu}^{1}{ }^{1}$, Jianping Zhu ${ }^{1}$, Jiayi Jin ${ }^{2}$, Lingyan $\mathrm{Yu}^{3, * \mathbb{D}}$ and Gang Han ${ }^{1, *}$ \\ 1 Department of Pharmacy, Sir Run Run Shaw Hospital, Zhejiang University School of Medicine, \\ Hangzhou 310016, China; yzw_srrsh@zju.edu.cn (Z.Y.); zjping@zju.edu.cn (J.Z.) \\ 2 Biomedical Research Center, Sir Run Run Shaw Hospital, Zhejiang University School of Medicine, \\ Hangzhou 310016, China; 13587224234@163.com \\ 3 Department of Pharmacy, Second Affiliated Hospital, Zhejiang University School of Medicine, \\ Hangzhou 310009, China \\ * Correspondence: lingyanyu@zju.edu.cn (L.Y.); 3199022@zju.edu.cn (G.H.)
}

check for

updates

Citation: Yu, Z.; Zhu, J.; Jin, J.; Yu, L.; Han, G. Trends in Outpatient Prescribing Patterns for Ocular Topical Anti-Infectives in Six Major Areas of China, 2013-2019. Antibiotics 2021, 10, 916. https://doi.org/ 10.3390/antibiotics10080916

Academic Editors: Rabia Hussain, Jaya Muneswarao and Zaheer Ud-Din Babar

Received: 30 June 2021

Accepted: 27 July 2021

Published: 28 July 2021

Publisher's Note: MDPI stays neutral with regard to jurisdictional claims in published maps and institutional affiliations.

Copyright: (c) 2021 by the authors. Licensee MDPI, Basel, Switzerland. This article is an open access article distributed under the terms and conditions of the Creative Commons Attribution (CC BY) license (https:// creativecommons.org/licenses/by/ $4.0 /)$.

\begin{abstract}
Topical anti-infectives are important in the management of ocular infections, but little is known about their current status and trends in their use in China. Thus, we carried out a prescriptionbased, cross-sectional study using the database of Hospital Prescription Analysis Projection of China, and aimed to analyze the trend in the use of ocular topical anti-infectives for outpatients of the ophthalmology department from 2013 to 2019. A total of 2,341,719 prescriptions from 61 hospitals located in six major areas written by ophthalmologists for outpatients were identified, and 1,002,254 of the prescriptions contained at least one anti-infective. The yearly anti-infective prescriptions increased continuously from 126,828 prescriptions in 2013 to 163,434 prescriptions in 2019. The cost also increased from 4,503,711 Chinese Yuan (CNY) in 2013 to CNY 5,860,945 in 2019. However, the use rate of anti-infectives decreased slightly from $46.5 \%$ in 2013 to $41.1 \%$ in 2019. Patients aged between 19 and 45 years old had the highest anti-infective use rate. Levofloxacin was the most frequently used anti-infective and kept on increasing among all age groups, occupying $67.1 \%$ of the total cost at the end of the study. Tobramycin was more frequently used in pediatric patients than in adults, but the use still decreased. Ganciclovir was the preferred anti-viral drug over acyclovir. In conclusion, the prescriptions and cost of ocular topical anti-infectives for outpatients both increased progressively. The increasingly widespread use of levofloxacin raised concerns regarding safety in pediatrics and resistance development. The observed trends can lead to the more efficient management of ocular anti-topical anti-infectives in China.
\end{abstract}

Keywords: antibiotic; ophthalmologist; levofloxacin; tobramycin; prescription; cost

\section{Introduction}

Topical ocular anti-infectives played an important role in the management of ocular infections, including conjunctivitis, keratitis, blepharitis endophthalmitis and dacryocystitis [1,2]. Treatment failure of ocular infections may lead to vision loss and blindness [3]. Moreover, anti-infectives are also commonly used in perioperative prophylaxis with various patterns [4]. It was reported that the use of ocular topical anti-infectives increased in some countries [5]. This raised concerns regarding the over-use and inappropriate use of topical anti-infectives [6].

The inappropriate use of anti-infectives, especially the over-use of antibiotics, may lead to the development of antimicrobial drug resistance [7]. In this case, infection treatment would be more difficult, as many anti-infectives have no suitable formulation for ocular use. Moreover, inappropriate use, especially overuse, corresponds to a substantial cost. It is reported that the cost of post-cataract surgery antibiotic use in 2016 in the U.S. was USD 170 million, and there is substantial opportunity to improve the value of care [8]. Hospital antimicrobial stewardship programs had been implemented and the appropriateness of 
antibiotic use was improved in recent years [9]. However, ocular topical anti-infectives were not always included in these programs. The inappropriate use of antibiotic eye drops seems to be common among ophthalmologists in China [10]. Thus, better management of these drugs is urgently needed. A drug utilization study is an essential tool for evaluating and monitoring the prescribing patterns and improving the quality of pharmacological therapy.

For now, little is known about the current status and trend in the use of ocular topical anti-infectives in China, and it is essential for future stewardship programs to develop this understanding. Thus, we carried out this prescription-based, cross-sectional study to evaluate trends in the use of topical anti-infectives during a seven-year period.

\section{Results}

\subsection{Total Trends in Prescriptions, Cost and Use Rate}

A total of 2,341,719 prescriptions from 61 hospitals written by ophthalmologists for outpatients were identified, and 1,002,254 of the prescriptions contained at least one ocular topical anti-infective. As shown in Figure 1A, the yearly anti-infective prescriptions increased continuously from 126,828 prescriptions in 2013 to 163,434 prescriptions in 2019 $(p=0.007)$. The yearly expenditure on anti-infectives also increased progressively from $4,503,711$ Chinese Yuan (CNY) in 2013 to CNY 5,860,945 in 2019 ( $p=0.016)$. However, the use rate of anti-infectives (referred to as the percentage of prescriptions that contained ocular topical anti-infectives) showed a slight but significant decreasing trend (Figure 1B, $p=0.005)$.
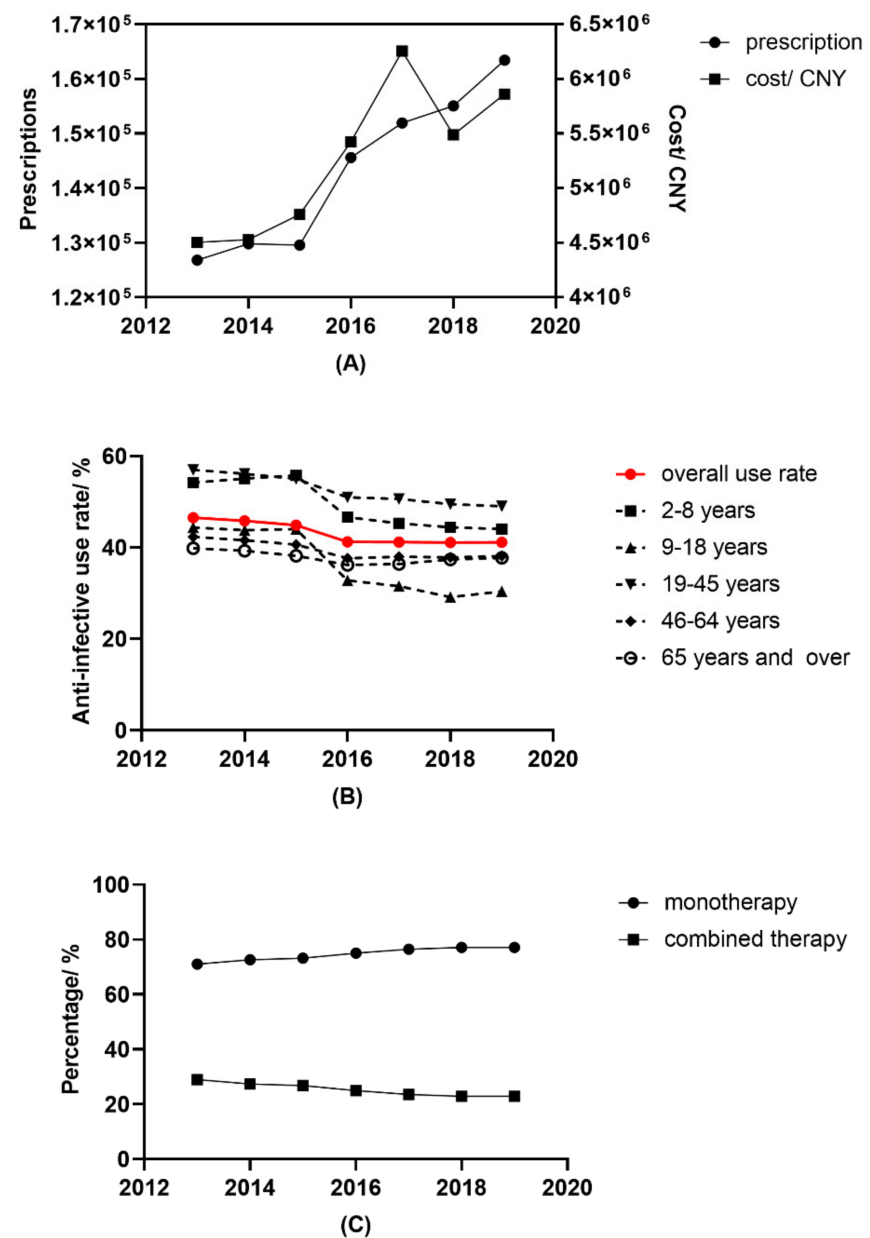

Figure 1. Trends in ocular topical anti-infective use in 61 sampling hospitals from 2013 and 2019. (A) Yearly prescriptions and cost; (B) overall use rate and age stratified use rate of ocular topical anti-infectives; (C) prescription patterns. 


\subsection{Trends Stratified by Age and Sex}

The demographic characteristics of patients who received anti-infective prescriptions are shown in Table 1. The numbers of anti-infective prescriptions for each age group all increased (all $p<0.05$ ). Patients aged between 19 and 45 years old constituted the majority of patients who consumed ocular topical anti-infectives. The proportions of each age group did not change substantially during the study period. However, as shown in Figure 1B, the percentages of prescriptions containing anti-infectives for each age group differed greatly. The use rate of patients aged 65 years and over was stable during the study period, while the rate of pediatric patients decreased significantly $(p=0.006$ for patients aged $2-8$ years; and $p=0.004$ for patients aged 9-18 years). Interestingly, patients aged between 19 and 45 years had the highest anti-infective use rate. Female patients were more common than males, about 1.3 times higher for each year, and but the ratios were not changed $(p>0.05)$. As shown in Figure 1C, monotherapy is the predominate pattern of topical anti-infective therapy, and its proportion kept on increasing during the seven-year period $(p<0.001)$.

Table 1. Demographic characteristics of study sample from 2013 to $2019^{1}$.

\begin{tabular}{|c|c|c|c|c|c|c|c|c|}
\hline & & 2013 & 2014 & 2015 & 2016 & 2017 & 2018 & 2019 \\
\hline \multirow[t]{5}{*}{ age } & $2-8$ years & $8424(6.64)$ & 9252(7.13) & 9703(7.49) & $10,837(7.44)$ & $11,139(7.33)$ & $11,696(7.56)$ & $12,720(7.78)$ \\
\hline & $9-18$ years & $5593(4.41)$ & $5746(4.43)$ & $5688(4.39)$ & $6206(4.26)$ & $6575(4.33)$ & $6644(4.29)$ & $7462(4.57)$ \\
\hline & $19-45$ years & $43,714(34.5)$ & $43,959(33.9)$ & $43,382(33.5)$ & $49,683(34.1)$ & $52,453(34.5)$ & $53,615(34.6)$ & $56,393(34.5)$ \\
\hline & 46-64 years & $37,951(29.9)$ & $38,426(29.6)$ & $37,680(29.1)$ & $42,131(28.9)$ & $43,425(28.6)$ & $42,872(27.7)$ & $44,338(27.1)$ \\
\hline & 65 years and over & $31,146(24.6)$ & $32,421(25.0)$ & $33,106(25.6)$ & $36,760(25.2)$ & $38,337(25.2)$ & $39,956(25.8)$ & $42,521(26.0)$ \\
\hline \multirow[t]{2}{*}{ sex } & male & $55,470(43.7)$ & $56,530(43.6)$ & $56,944(44.0)$ & $63,803(43.8)$ & $65,750(43.3)$ & $66,418(42.8)$ & $70,417(43.1)$ \\
\hline & female & $71,358(56.3)$ & $73,274(56.4)$ & $72,615(56.0)$ & $81,814(56.2)$ & $86,179(56.7)$ & $88,665(57.2)$ & $93,017(56.9)$ \\
\hline
\end{tabular}

${ }^{1}$ Data were represented as prescriptions (percentage $\%$ ).

\subsection{Stratified by Drug}

The yearly prescriptions of each specific drug and corresponding cost are shown in Tables 2 and 3. Antibiotics were the main prescribed anti-infectives. Levofloxacin was the most frequently used topical inti-infective, and its use rate among anti-infective prescriptions continued to increase $(p=0.007)$. The cost of levofloxacin also increased ( $p=0.016$ ) and occupied $67.1 \%$ of the total cost of topical anti-infectives at the end of the study. Ofloxacin decreased both in prescription numbers and percentages $(p=0.007$ and $p<0.001)$. Tobramycin showed a decreasing trend; however, its combination with dexamethasone increased progressively both in prescription numbers and portions $(p=0.003$ and $p<0.001)$. We also analyzed the trends in use of levofloxacin and tobramycin in different age groups (Figure 2). The use of levofloxacin increased in all age groups (all $p<0.05$ ). In contrast, tobramycin showed a decreasing trend in all age groups (all $p<0.05)$. However, the magnitude of the decrease in pediatric patients was smaller than that in adults, and still covered $32.7 \%$ of patients aged between 2 and 8 years old. The most frequently used anti-viral drug was ganciclovir, and anti-fungal drugs were rarely used. 
Table 2. Numbers of ocular topical anti-infectives prescriptions from 2013 to $2019^{1}$.

\begin{tabular}{|c|c|c|c|c|c|c|c|}
\hline Drugs & 2013 & 2014 & 2015 & 2016 & 2017 & 2018 & 2019 \\
\hline Levofloxacin & $67,077(52.9)$ & $70,329(54.5)$ & $86,020(66.4)$ & $99,232(68.1)$ & $105,462(69.4)$ & $107,437(69.3)$ & $117,406(71.8)$ \\
\hline Ofloxacin & $34,176(26.9)$ & $33,068(25.6)$ & $25,487(19.7)$ & $27,503(18.9)$ & $22,735(15.0)$ & $21,651(14.0)$ & $20,550(12.6)$ \\
\hline Tobramycin/dexamethasone & $17,187(13.6)$ & $17,356(13.4)$ & $18,500(14.3)$ & $23,004(15.8)$ & $23,950(15.8)$ & $26,720(17.2)$ & $28,564(17.5)$ \\
\hline Tobramycin & $17,248(13.6)$ & $17,723(13.7)$ & $11,947(9.22)$ & $11,748(8.07)$ & $12,536(8.25)$ & $12,862(8.29)$ & $13,039(7.98)$ \\
\hline Erythromycin & $5152(4.06)$ & $5710(4.42)$ & $4502(3.47)$ & 4493(3.09) & $5364(3.53)$ & $5974(3.85)$ & $6065(3.71)$ \\
\hline Gatifloxacin & $3839(3.03)$ & $3470(2.69)$ & $2274(1.76)$ & $2180(1.5)$ & $3274(2.15)$ & 2947(1.9) & 1917(1.17) \\
\hline Lomefloxacin & $2552(2.01)$ & $1698(1.32)$ & $1579(1.22)$ & $921(0.63)$ & $270(0.18)$ & 161(0.1) & 251(0.15) \\
\hline Chlortetracycline & 2088(1.65) & 2019(1.56) & $1535(1.18)$ & $1419(0.97)$ & $1726(1.14)$ & $1850(1.19)$ & $2036(1.25)$ \\
\hline Sodium hyaluronate/chloramphenicol & 1491(1.18) & $1339(1.04)$ & $1246(0.96)$ & $934(0.64)$ & $1269(0.84)$ & $856(0.55)$ & $1755(1.07)$ \\
\hline Lincomycin & $1233(0.97)$ & $1130(0.88)$ & $329(0.25)$ & $480(0.33)$ & $1127(0.74)$ & $1027(0.66)$ & $407(0.25)$ \\
\hline Chloromycetin & $1060(0.84)$ & 1167(0.9) & 1015(0.78) & $683(0.47)$ & $510(0.34)$ & $346(0.22)$ & $215(0.13)$ \\
\hline Compound neomycin eye drops & $951(0.75)$ & $1118(0.87)$ & $1049(0.81)$ & $379(0.26)$ & $105(0.07)$ & $124(0.08)$ & $42(0.03)$ \\
\hline Rifampicin & $573(0.45)$ & $401(0.31)$ & 113(0.09) & $42(0.03)$ & $10(0.01)$ & $13(0.01)$ & $9(0.01)$ \\
\hline Tetracycline/cortisone & $272(0.21)$ & $365(0.28)$ & $163(0.13)$ & - & - & - & - \\
\hline Sulfacetamide sodium & $153(0.12)$ & $129(0.10)$ & $121(0.09)$ & $123(0.08)$ & $77(0.05)$ & $24(0.02)$ & - \\
\hline Neomycin & $93(0.07)$ & $68(0.05)$ & $38(0.03)$ & $4(0.00)$ & $15(0.01)$ & $4(0.00)$ & - \\
\hline Amikacin & $51(0.04)$ & $40(0.03)$ & $9(0.01)$ & $6(0.00)$ & $9(0.01)$ & $3(0.00)$ & - \\
\hline Norfloxacin & $50(0.04)$ & $83(0.06)$ & $44(0.03)$ & $21(0.01)$ & $1(0.00)$ & - & - \\
\hline Fusidic acid & $43(0.03)$ & $42(0.03)$ & $13(0.01)$ & $18(0.01)$ & $2(0.00)$ & - & - \\
\hline Ciprofloxacin & $22(0.02)$ & $15(0.01)$ & $2(0.00)$ & - & - & - & - \\
\hline gentamicin/fluorometholone & - & - & - & - & 282(0.19) & $332(0.21)$ & $205(0.13)$ \\
\hline Ganciclovir & $6831(5.39)$ & 6512(5.04) & 7093(5.47) & $8139(5.59)$ & $8761(5.77)$ & 7953(5.13) & $7669(4.69)$ \\
\hline Acyclovir/sodium hyaluronate & $2508(1.98)$ & $2345(1.82)$ & 2477(1.91) & 2445(1.68) & 2301(1.51) & 2335(1.51) & 2813(1.72) \\
\hline Acyclovir & $2729(2.15)$ & $2508(1.94)$ & $1606(1.24)$ & 1005(0.69) & $538(0.35)$ & $412(0.27)$ & $385(0.24)$ \\
\hline Ribavirin & 592(0.47) & $474(0.37)$ & $442(0.34)$ & $309(0.21)$ & $354(0.23)$ & $299(0.19)$ & $423(0.26)$ \\
\hline Ftibamzone & $44(0.03)$ & $21(0.02)$ & - & - & - & - & - \\
\hline Natamycin & $16(0.01)$ & - & $5(0.00)$ & $44(0.03)$ & $35(0.02)$ & $28(0.02)$ & $66(0.04)$ \\
\hline Fluconazole & - & - & - & $3(0.00)$ & - & $1(0.00)$ & $2(0.00)$ \\
\hline
\end{tabular}

${ }^{1}$ Data are represented as prescriptions (percentage \%).

Table 3. Expenditure on ocular topical anti-infectives dispensed from 2013 to $2019^{1}$.

\begin{tabular}{|c|c|c|c|c|c|c|c|}
\hline Drug & 2013 & 2014 & 2015 & 2016 & 2017 & 2018 & 2019 \\
\hline Levofloxacin & $2,342,514(52.0)$ & $2,453,344(54.2)$ & $2,875,647(60.4)$ & $3,372,923(62.2)$ & $4,094,023(65.5)$ & $3,575,850(65.2)$ & $3,931,192(67.1)$ \\
\hline Ofloxacin & $749,390(16.6)$ & $714,976(15.8)$ & $640,714(13.5)$ & $636,032(11.7)$ & $544,397(8.70)$ & $437,614(7.97)$ & $419,011(7.15)$ \\
\hline Tobramycin/dexamethasone & $581,239(12.9)$ & $587,307(13.0)$ & $616,420(13.0)$ & $749,588(13.8)$ & $818,469(13.1)$ & $804,675(14.7)$ & $845,147(14.4)$ \\
\hline Tobramycin & $352,569(7.83)$ & $352,601(7.79)$ & $249,359(5.24)$ & $248,459(4.58)$ & $277,593(4.44)$ & $235,096(4.28)$ & $236,677(4.04)$ \\
\hline Ganciclovir & $215,112(4.78)$ & $200,949(4.44)$ & $208,749(4.39)$ & $226,533(4.18)$ & $230,249(3.68)$ & $191,290(3.49)$ & $182,981(3.12)$ \\
\hline Other & $262,887(5.84)$ & $219,362(4.84)$ & $168,587(3.54)$ & $189,612(3.50)$ & $290,198(4.64)$ & $243,031(4.43)$ & $245,938(4.20)$ \\
\hline
\end{tabular}

${ }^{1}$ Data are represented as cost in Chinese Yuan (percentage \%).
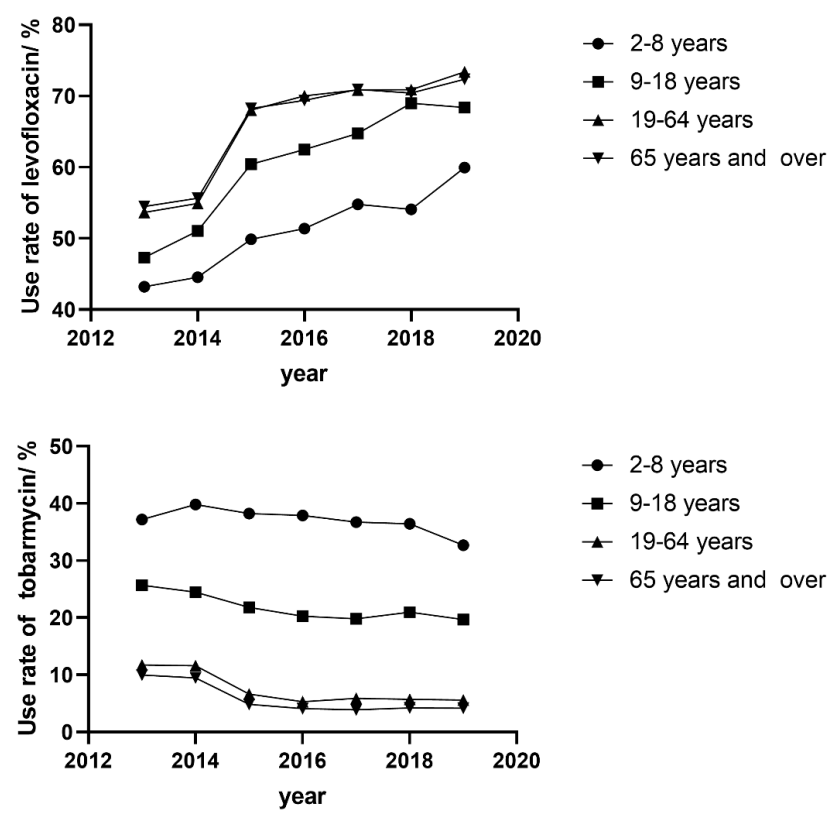

Figure 2. Trends in use rate of levofloxacin (top) and tobramycin (bottom). 


\section{Discussion}

To the best of our knowledge, this was the first study that described the trends in ocular topical anti-infectives use in Chinese outpatients. As a large number of prescriptions from 61 sampling hospitals were included, the results are nationally representative. The prescription of ocular topical anti-infectives and the corresponding cost both increased during the seven-year period, but the percentage of prescriptions containing ocular topical anti-infectives declined. Antibiotics were the main anti-infectives, and levofloxacin was the favored anti-infective drug.

As the percentage of prescriptions containing ocular topical anti-infectives decreased, the increased number of prescriptions of topical anti-infectives may be due to increased demand and supply of ocular healthcare in China [11]. The reason for this decline may be the antimicrobial stewardship program in the ophthalmology departments. The corresponding cost was parallel to the increased prescriptions; thus, the health care system should be prepared to face increasing economic pressure. We noted that the cost dropped in 2018-this be may due to the implementation of the National Drug Centralized Procurement Program of China [12].

Significant differences in antibiotic use were found among countries. A populationbased registry study was carried out to assess the ocular anti-infective use from 2015 to 2019 in a region of Spain. The results show that ocular topical anti-infectives were distributed to $5.38 \%$ of the population, and the use is increasing [5]. A study carried out in Demark, Norway and Sweden aimed to analyze ocular topical antibiotic use in children aged 0-4 years from 2000 to 2015. The incidence rate was stable between 2000 and 2010, and then declined [13]. It is reported that differences in healthcare systems, national guidelines and school and day care policies may contribute to the differences in antibiotic use [13]. Thus, improving these issues may lower the use of ocular anti-infectives.

Although there is a lack of direct comparisons with other countries, the approximately $40 \%$ prescription rate of anti-infectives in China raised concerns regarding the overuse of anti-infectives in ophthalmology departments. Topical anti-infectives are usually prescribed for ocular infection and perioperative prophylaxis. The most common ocular infection was reported to be conjunctivitis, and most cases of conjunctivitis are due to virus infection and are self-limiting, and thus, no antibiotic should be administered [6,14]. Even in the case of acute bacterial conjunctivitis, antibiotics are only recommended in severe cases [6]. Antibiotics were also found to be the most common medication prescribed for cataract surgery in some countries [15]. Nowadays, postoperative administration of topical antibiotics in noncomplicated cataract surgery, the most common clean surgery in ophthalmology, is a standard procedure that prevents and lowers endophthalmitis rates. However, some ophthalmologists use antibiotics in preoperative care, before the surgery, which is not proven to be beneficial for patients [16-18]. Moreover, in different ocular procedures, such as intravitreal injections, antibiotics administration is contraindicated [19]. The overuse of anti-infectives may be due to a lack of awareness of evidence or guidelines, institutionalized teaching or defensive practice [6].

When the anti-infective use was stratified by age, the highest use rate was found in patients aged between 19 and 45 years old, followed by patients aged between 2 and 8 years old. Thus, special attention should be paid to patients at these ages. It is not surprising that children had high anti-infective use, as the prevalence of bacterial ocular infection was high in patients at this age [14]. A higher use rate was also found in children in other countries [5]. However, the reason for the high use rate in adult patients is unknown.

Levofloxacin was the most frequently used antibiotic, and its use increased continuously during the study period. This situation was quite different from other countries. Tobramycin, including its combinations, is the most widely used anti-infective in Spain [5]. Chloramphenicol and fusidic acid were frequently used in pediatric patients in Denmark, Norway and Sweden [13]. Fluoroquinolones was frequently used for American postsurgery patients, but ofloxacin was the most common, while moxifloxacin and besifloxacin were the costliest antibiotics [15]. Tobramycin and fluoroquinolones are considered first- 
line drugs for the most common ocular infection, bacterial conjunctivitis [20]. Common organisms had similar susceptibility to levofloxacin and tobramycin, and these drugs had comparable efficacy in some ocular infections [21,22]. The continuously increasing use rate of levofloxacin should be noticed.

The systemic use of fluoroquinolones in children was warned against due to adverse drug reactions such as musculoskeletal events [23]. However, the safety of the topical use of fluoroquinolones in pediatric patients was controversial at one time [24]. Ophthalmologists were concerned about the safety of topical levofloxacin at the beginning of the study and tobramycin was frequently used in pediatric patients, and the use rate of levofloxacin in pediatric patients was much lower than that in adults. Recent studies considered that there was no evidence for harm caused by topical fluoroquinolone use in pediatrics [25-28]. Additionally, this might be the reason for the increasing use of levofloxacin in pediatric patients. However, the widespread use of levofloxacin raised concern regarding resistance development in common ocular pathogens [29].

Chloramphenicol and fusidic acid are also recognized as first-line treatments for some ocular infections; however, these drugs are seldom used in China. Chloramphenicol eye drops are cheap, have little irritative effect on the cornea and cover a broad spectrum of bacteria found in infections of the cornea or conjunctivae [30]. However, a probable association with aplastic anemia and high resistance in China are the reasons for its low use $[22,30]$.

Ganciclovir was the most favorable ocular topical anti-viral drug in this study. However, it is more costly than acyclovir, which was the most widely used topical anti-infective in ocular viral infections in other countries [5]. There are a variety of ocular viral diseases caused by different types of viruses. Human adenovirus is the most common cause of infection on the ocular surface, accounting for up to $75 \%$ of conjunctivitis cases. Possible therapeutic benefits in adenovirus infection have been demonstrated through the use of antiviral drugs such as ganciclovir, ribavirin and cidofovir. The ophthalmic formulation of ganciclovir is used commonly in cases of adenovirus conjunctivitis and keratitis, which is superior to acyclovir [31-33]. However, ganciclovir was not superior to acyclovir in ocular human herpesvirus infection, another leading cause of infectious blindness [34]. Attention should be paid to the rational use of topical antiviral drugs. Anti-fungal drugs were seldom used, which was in accordance with the low prevalence of diagnosed ocular fungal infection [35]. Moreover, oral formulations and off-label use of injectable formulations are often used, but were not included for analysis in this study [36].

There were also some limitations of our research. Only prescriptions issued by ophthalmologists were included. The diagnosis was not included for analysis; thus, the appropriateness of topical anti-infective use was not evaluated. Most of the included hospitals were tertiary hospitals and sampling bias may exist.

\section{Methods}

\subsection{Study Design and Data Source}

This study was designed as a prescription-based, cross-sectional study. Ethical approval was obtained from the Ethical Committee of Sir Run Run Shaw Hospital, Zhejiang University School of Medicine (KEYAN20191011-18). Informed consent was waived as part of approval due to the nature of the study. The prescriptions were extracted from the database of the Hospital Prescription Analysis Cooperative Project. This database is widely used for pharmaco-epidemiology studies in China [37-42]. The database contains prescription information of participating hospitals on 40 random days each year. The prescription information covered prescription code, date, sex and age of patient, department of physician, drug name and cost.

\subsection{Prescription Inclusion}

Prescriptions meeting the following criteria were included for analysis: (1) prescriptions written by physicians of ophthalmology department; (2) prescriptions written for 
outpatients aged over 2 years during a study period from 2013 to 2019; (3) prescriptions from hospitals located in six major areas of China (Beijing, Shanghai, Guangzhou, Chengdu, Hangzhou, Tianjin) and hospitals that participated in the program continuously during the study period.

Topical drugs belonging to the S01A category and S01C category of ATC/DDD Index were defined as ocular topical anti-infectives [43]. Anti-infectives, including antibacterial drugs, anti-viral drugs and anti-fungal drugs, in the prescriptions were labeled for processing.

\subsection{Data Analysis}

The total yearly prescriptions and prescriptions containing topical anti-infectives written by ophthalmologists were counted. Then, the percentage of prescriptions that contained topical anti-infectives was calculated. The yearly expenditure on ocular topical anti-infectives was also added up. The yearly trends were analyzed and further stratified by age, sex and specific drug. The treatment pattern of ocular topical anti-infectives was also analyzed. The trends in yearly prescription numbers and cost were tested by the Mann-Kendal test, and the trends in percentages were tested by the log-linear test. All statistical tests were carried out in R V4.0.5 software.

\section{Conclusions}

Although the overall use rate declined during the study period, the number of prescriptions containing ocular topical anti-infectives increased progressively. Additionally, this raised concerns regarding inappropriate anti-infective use in outpatients of the ophthalmology department in China. The healthcare system may face the pressures of cost and the emergence of resistance. Ophthalmologists should follow the best clinical evidence to improve appropriate anti-infection therapy. Levofloxacin was prescribed most frequently, and its use increased among all age groups, including pediatric patients. However, resistance to levofloxacin among common pathogens causing ocular infections should be monitored closely. The observed trends can lead to the more efficient management of ocular anti-topical anti-infectives in China.

Author Contributions: Conceptualization, L.Y. and G.H.; Methodology, Z.Y.; Software, Z.Y. and J.Z.; Validation, Z.Y., J.Z. and J.J.; Formal Analysis, Z.Y.; Investigation, Z.Y., J.Z. and J.J.; Resources, Z.Y.; Data Curation, Z.Y.; Writing-Original Draft Preparation, Z.Y., J.Z. and J.J.; Writing-Review and Editing, L.Y. and G.H.; Visualization, L.Y.; Supervision, L.Y. and G.H.; Project Administration, L.Y. and G.H.; Funding Acquisition, Z.Y. All authors have read and agreed to the published version of the manuscript.

Funding: This work was funded by Zhejiang Pharmaceutical Association (2010ZYY01).

Institutional Review Board Statement: The study was conducted according to the guidelines of the Declaration of Helsinki, and approved by Ethical Committee of Sir Run Run Shaw Hospital, Zhejiang University School of Medicine (KEYAN20191011-18, 14 October 2019).

Informed Consent Statement: Informed consent was waived as part of approval due to the nature of the study.

Data Availability Statement: Data is contained within the article.

Acknowledgments: We would thank Hospital Prescription Analysis Cooperative Project for collecting and providing the data.

Conflicts of Interest: The authors declare no conflict of interest.

\section{References}

1. Leung, A.K.; Hon, K.L.; Wong, A.H.; Wong, A.S. Bacterial conjunctivitis in childhood: Etiology, clinical manifestations, diagnosis and management. Recent Pat. Inflamm. Allergy Drug Discov. 2018, 12, 120-127. [CrossRef] [PubMed]

2. Austin, A.; Lietman, T.; Rose-Nussbaumer, J. Update on the Management of Infectious Keratitis. Ophthalmology 2017, 124, 1678-1689. [CrossRef] [PubMed] 
3. Robbins, C.B.; Feng, H.L.; Wisely, C.E.; Daluvoy, M.; Fekrat, S. Endophthalmitis after Descemet Stripping Endothelial Keratoplasty: Microbiological Yield and Visual Outcomes. Am. J. Ophthalmol. 2021, 222, 34-40. [CrossRef] [PubMed]

4. Fay, A.; Nallasamy, N.; Bernardini, F.; Wladis, E.J.; Durand, M.L.; Devoto, M.H.; Meyer, D.; Hartstein, M.; Honavar, S.; Osaki, M.H.; et al. Multinational Comparison of Prophylactic Antibiotic Use for Eyelid Surgery. JAMA Ophthalmol. 2015, 133, 778-784. [CrossRef]

5. Gutiérrez-Abejón, E.; Herrera-Gómez, F.; Ayestarán-Martínez, I.J.; Álvarez, F.J. Trend in the use of topical ocular anti-infectives in a region of Spain between 2015 and 2019: A population-based registry study. Rev. Española Quimioter. 2020, 33, 453-458. [CrossRef]

6. Fayers, T.; Loh, G.K.; Cordeiro, M.F.; Lee, V.; Jain, R.; Fayers, P.M. Overprescribing of antibiotics by UK ophthalmologists. Eye 2018, 32, 240-242. [CrossRef]

7. Lee, J.; Iwasaki, T.; Ohtani, S.; Matsui, H.; Nejima, R.; Mori, Y.; Kagaya, F.; Yagi, A.; Yoshimura, A.; Hanaki, H.; et al. Benzalkonium chloride resistance in staphylococcus epidermidis on the ocular surface of glaucoma patients under long-term administration of eye drops. Transl. Vis. Sci. Technol. 2020, 9, 1-8. [CrossRef]

8. Crowell, E.L.; Koduri, V.A.; Groat, R.S.; Lee, D.A. Cost comparison of commonly used postoperative topical ophthalmic antibiotics. J. Cataract Refract. Surg. 2017, 43, 1322-1327. [CrossRef]

9. Xiao, Y.; Shen, P.; Zheng, B.; Zhou, K.; Luo, Q.; Li, L. Change in antibiotic use in secondary and tertiary hospitals nationwide after a national antimicrobial stewardship campaign was launched in china, 2011-2016: An observational study. J. Infect. Dis. 2020, 221, S148-S155. [CrossRef]

10. Chen, Z.; Jiang, J.; Xu, J.; Yang, X.; Yang, Y.; Wang, K.; Song, H.; Yang, B.; Cho, P. Antibiotic eye drops prescription patterns by orthokeratology practitioners in China and the development of antibiotic usage guidelines. Contact Lens Anterior Eye 2020, 1-6. [CrossRef]

11. Yuan, M.; Chen, W.; Wang, T.; Song, Y.; Zhu, Y.; Chen, C.; Yang, Y.; Liu, Y.; Li, Y.; Lin, H. Exploring the growth patterns of medical demand for eye care: A longitudinal hospital-level study over 10 years in China. Ann. Transl. Med. 2020, 8, 1374. [CrossRef]

12. Chen, L.; Yang, Y.; Luo, M.; Hu, B.; Yin, S.; Mao, Z. The impacts of national centralized drug procurement policy on drug utilization and drug expenditures: The case of Shenzhen, China. Int. J. Environ. Res. Public Health 2020, 17, 1-11. [CrossRef]

13. Andersson, J.; Hofsli, M.; Gade, U.L.; Heegaard, S.; Pottegård, A. Use of topical ocular antibiotics in young children: A Scandinavian drug utilization study. Acta Ophthalmol. 2018, 96, 789-794. [CrossRef]

14. Varu, D.M.; Rhee, M.K.; Akpek, E.K.; Amescua, G.; Farid, M.; Garcia-Ferrer, F.J.; Lin, A.; Musch, D.C.; Mah, F.S.; Dunn, S.P. Conjunctivitis Preferred Practice Pattern ${ }^{\circledR}$. Ophthalmology 2019, 126, 94-169. [CrossRef]

15. Zafar, S.; Wang, P.; Schein, O.D.; Srikumaran, D.; Makary, M.; Woreta, F.A. Prescribing Patterns and Costs Associated with Postoperative Eye Drop Use in Medicare Beneficiaries Undergoing Cataract Surgery. Ophthalmology 2020, 127, 573-581. [CrossRef]

16. Aragona, P.; Postorino, E.I.; Aragona, E. Post-surgical management of cataract: Light and dark in the 2020s. Eur. J. Ophthalmol. 2021, 31, 287-290. [CrossRef]

17. Bandello, F.; Coassin, M.; Di Zazzo, A.; Rizzo, S.; Biagini, I.; Pozdeyeva, N.; Sinitsyn, M.; Verzin, A.; De Rosa, P.; Calabro, F.; et al. One Week of Levofloxacin Plus Dexamethasone Eye Drops for Cataract Surgery: An Innovative and Rational Therapeutic Strategy. Eye 2020, 34, 2112-2122. [CrossRef]

18. Gower, E.W.; Lindsley, K.; Nanji, A.A.; Leyngold, I.; Mcdonnell, P.J. Perioperative antibiotics for prevention of acute endophthalmitis after cataract surgery. Cochrane Database Syst. Rev. 2013, 7, CD006364. [CrossRef]

19. Yin, V.T.; Weisbrod, D.J.; Eng, K.T.; Schwartz, C.; Kohly, R.; Mandelcorn, E.; Lam, W.C.; Daneman, N.; Simor, A.; Kertes, P.J. Antibiotic resistance of ocular surface flora with repeated use of a topical antibiotic after intravitreal injection. JAMA Ophthalmol. 2013, 131, 456-461. [CrossRef]

20. Azari, A.A.; Barney, N.P. Conjunctivitis: A systematic review of diagnosis and treatment. JAMA J. Am. Med. Assoc. 2013, 310, 1721-1729. [CrossRef]

21. Accorinti, M.; Colao, L.; Gilardi, M.; Cecere, M.; Salotti, A.; Pesci, F.R. Levofloxacin and Tobramycin for Severe Bacterial Keratouveitis. Ocul. Immunol. Inflamm. 2016, 24, 482-488. [CrossRef]

22. Wang, N.; Huang, Q.; Tan, Y.W.; Lin, L.P.; Wu, K.L. Bacterial spectrum and resistance patterns in corneal infections at a Tertiary Eye Care Center in south China. Int. J. Ophthalmol. 2016, 9, 384-389. [CrossRef]

23. Noel, G.J.; Bradley, J.S.; Kauffman, R.E.; Duffy, C.M.; Gerbino, P.G.; Arguedas, A.; Bagchi, P.; Balis, D.A.; Blumer, J.L. Comparative safety profile of levofloxacin in 2523 children with a focus on four specific musculoskeletal disorders. Pediatr. Infect. Dis. J. 2007, 26, 879-891. [CrossRef]

24. Jackson, M.A.; Schutze, G.E.; Byington, C.L.; Maldonado, Y.A.; Barnett, E.D.; Campbell, J.D.; Davies, H.D.; Lynfield, R.; Munoz, F.M.; Nolt, D.; et al. The use of systemic and topical fluoroquinolones. Pediatrics 2016, 138, e20162706. [CrossRef]

25. Sun, H.; Temeck, J.W.; McCune, S.K.; Chambers, W.A. Using Historical Data to Support Approval of Drug Products for Ophthalmia Neonatorum: Innovative Approach toward Evidence-Based Medicine. JAMA Ophthalmol. 2021, 139, 214-217. [CrossRef]

26. Comstock, T.L.; Paterno, M.R.; Usner, D.W.; Pichichero, M.E. Efficacy and safety of besifloxacin ophthalmic suspension 0.6 in children and adolescents with bacterial conjunctivitis: A post hoc, subgroup analysis of three randomized, double-masked, parallel-group, multicenter clinical trials. Pediatr. Drugs 2010, 12, 105-112. [CrossRef]

27. Lichtenstein, S.J.; Rinehart, M. Efficacy and safety of $0.5 \%$ levofloxacin ophthalmic solution for the treatment of bacterial conjunctivitis in pediatric patients. J. Am. Assoc. Pediatr. Ophthalmol. Strabismus 2003, 7, 317-324. [CrossRef] 
28. Khalili, S.; Imtirat, A.; Williams, S.; Ali, A.; Tehrani, N.; Mireskandari, K. Safety of intracameral moxifloxacin in the pediatric population: An equivalence study. J. Cataract Refract. Surg. 2020, 46, 228-234. [CrossRef]

29. Deguchi, H.; Kitazawa, K.; Kayukawa, K.; Kondoh, E.; Fukumoto, A.; Yamasaki, T.; Kinoshita, S.; Sotozono, C. The trend of resistance to antibiotics for ocular infection of Staphylococcus aureus, coagulase-negative staphylococci, and Corynebacterium compared with 10-years previous: A retrospective observational study. PLoS ONE 2018, 13, e0203705. [CrossRef]

30. Andaluz-Scher, L.; Medow, N.B. Chloramphenicol Eye Drops: An Old Dog in a New House. Ophthalmology 2020, 127, 1289-1291. [CrossRef]

31. Huang, J.; Kadonosono, K.; Uchio, E. Antiadenoviral effects of ganciclovir in types inducing keratoconjunctivitis by quantitative polymerase chain reaction methods. Clin. Ophthalmol. 2014, 8, 315-320. [CrossRef] [PubMed]

32. Wold, W.S.; Toth, K. New drug on the horizon for treating adenovirus. Expert Opin. Pharmacother. 2015, 16, 2095-2099. [CrossRef] [PubMed]

33. Ying, B.; Tollefson, A.E.; Spencer, J.F.; Balakrishnan, L.; Dewhurst, S.; Capella, C.; Buller, R.M.L.; Toth, K.; Wold, W.S.M. Ganciclovir inhibits human adenovirus replication and pathogenicity in permissive immunosuppressed syrian hamsters. Antimicrob. Agents Chemother. 2014, 58, 7171-7181. [CrossRef] [PubMed]

34. Wilhelmus, K.R. Antiviral treatment and other therapeutic interventions for herpes simplex virus epithelial keratitis. Cochrane Database Syst. Rev. 2015, 1, CD002898. [CrossRef] [PubMed]

35. Liu, M.Y.; Zhang, L.; Yin, X.L.; Sun, S.Y. Endophthalmitis associated with fungal keratitis and penetrating injuries in North China. Eur. J. Ophthalmol. 2020, 30, 455-461. [CrossRef]

36. Lakhani, P.; Patil, A.; Majumdar, S. Challenges in the Polyene- and Azole-Based Pharmacotherapy of Ocular Fungal Infections. J. Ocul. Pharmacol. Ther. 2019, 35, 6-22. [CrossRef]

37. Yu, Z.; Zhang, J.; Zheng, Y.; Yu, L. Trends in Antidepressant Use and Expenditure in Six Major Cities in China From 2013 to 2018. Front. Psychiatry 2020, 11, 551. [CrossRef]

38. Yu, Z.; Yu, L.; Shan, C. Trends of ambulatory oral anticoagulant prescription in five major cities of China, 2012-2017. BMC Health Serv. Res. 2020, 20, 209. [CrossRef]

39. Yu, Z.; Yu, L.; Zhu, J. Patterns of polymyxin B use in eight major cities of China in its first year of use. J. Glob. Antimicrob. Resist. 2020, 20, 342-343. [CrossRef]

40. Yu, L.; Ding, K.; Luo, L.; Yu, Z. Prescribing trends of glaucoma drugs in six major cities of China from 2013 to 2017. PLoS ONE 2020, 15, e0227595. [CrossRef]

41. Ying, J.; Li, L.C.; Wu, C.Y.; Yu, Z.W.; Kan, L. Di The status of proton pump inhibitor use: A prescription survey of 45 hospitals in China. Rev. Esp. Enferm. Dig. 2019, 111, 738-743. [CrossRef]

42. Yu, L.; Chen, X.; Yu, Z. Trends of antidementia drugs use in outpatients with Alzheimer's disease in six major cities of China: 2012-2017. Int. Clin. Psychopharmacol. 2019, 34, 312-316. [CrossRef]

43. WHO Collaborating Centre for Drug Statistics Methodology. ATC Classification Index with DDDs, 2021; WHO Collaborating Centre for Drug Statistics Methodology: Oslo, Norway, 2020. 